

\section{Transitioning together: A narrative analysis of the support accessed by partners of trans people}

Dr Jos Twist (corresponding author)

University of Hertfordshire; Doctorate in Clinical Psychology Programme Dept. of Psychology, University of Hertfordshire, College Lane, Hatfield, AL10 9AB, UK 07425 151982, jostwist@gmail.com

Dr Jos Twist is a newly qualified Clinical Psychologist who currently works at the Gender Identity Development Service for young people at the Tavistock and Portman National Health Service Foundation Trust.

\section{Dr Meg-John Barker}

Psychology in Arts and Social Sciences, The Open University, Walton Hall, Milton Keynes, MK7 6AA, UK

01908 655378; meg.john.barker@gmail.com

Dr. Meg-John Barker is a writer, therapist, and activist-academic specialising in sex, gender and relationships. Meg-John is a senior lecturer in psychology at the Open University and a UKCP accredited psychotherapist, and has over a decade of experience researching and publishing on these topics including the popular book Rewriting the Rules. 


\section{Dr Pieter W Nel}

University of Hertfordshire; Doctorate in Clinical Psychology Programme, Dept. of Psychology, University of Hertfordshire, College Lane, Hatfield, AL10 9AB, UK 01707 286322; p.w.nel@herts.ac.uk

Dr Pieter W Nel is Programme Director and Reader in Clinical Psychology Training at the University of Hertfordshire and practices as a Consultant Clinical Psychologist. He has a broad interest in alternatives to more orthodox approaches to clinical psychology education and practice, including non-pathologising and relational models of working with people in psychological distress.

\section{Dr Nic Horley}

University of Hertfordshire; Doctorate in Clinical Psychology Programme, Dept. of Psychology, University of Hertfordshire, College Lane, Hatfield, AL10 9AB, UK 07791571 167: nicola.horley@hotmail.com

Nic Horley is a Clinical Psychologist working in the NHS in London. Nic's clinical work and background is in personality disorder and complex mental health difficulties. Nic completed her doctoral research in the Narratives of people living with Gender Variance; gender and sexuality is an area of importance and passion for Nic. 


\section{Transitioning together: A narrative analysis of the support accessed by partners of trans people}

Historically trans people have often wrongly been advised that the gender role transition process will result in the breakdown of their relationships (Lev, 2004), and couples have often been provided with little support through this process. This paper presents an in-depth narrative analysis of the accounts of six cisgender women who have been partnered with trans individuals. It focuses on the support that non-trans partners accessed while their partner progressed through their gender transition. Support was deemed important by all participants in relation to their aim of remaining together with their partners. In terms of whom they accessed support from, participants spoke about interactions with other people in similar situations, with professional therapists, with the Gender Identity Clinics (GICs), and with their partners. In regards to therapy, some reported that their partner's transition was a topic they did not need to discuss. Many reported they had to take an "educator" role in therapy, suggesting that more training for therapists is required. Those who attended GICs with their partner were ambivalent about whether they would have utilised support there if it had been available there, stating that locally situated support was preferable. The paper draws out the clinical implications in relation to these areas.

Keywords: transgender, trans, couple relationships, cisgender, partners, support. 


\section{Introduction}

This paper presents the findings of a narrative inquiry and analysis into the experiences of support accessed by partners of trans people. The results are part of a larger study that examined the sexuality of those partnered with trans people. We first contextualise this study in the existing literature on trans people's relationships and support requirements. After presenting the analysis we draw out the implications for therapeutic practices.

Historically, it had been assumed that trans people’s partnerships would not continue through gender role transition (Lev, 2004), as relationships with trans people were considered to be unhealthy and unsatisfying (Benjamin, 1966). Moreover, those who stayed with a trans partner were seen as delusional or inadequate (Huxley, Kenna, \& Brandon, 1981) and their attraction was viewed as pathological (Steiner \& Bernstein, 1981). Negative discourses around trans partnerships still exist today with sexual, or romantic attraction to trans people being seen as pathological by some (Kins, Hoebeke, Heylens, Rubens \& De Cuypere, 2008) and a fetish by others (Serano, 2007; Tompkins, 2014).

Despite these negative discourses research has shown that trans people are able to form and maintain satisfactory and stable relationships. Lawrence (2005) found that $30 \%$ of the 232 trans women surveyed reported still being in a relationship that started at least a year before their Gender Confirmation Surgery. Moreover, Meier, Sharp, Michonski, Babcock and Fitzgerald (2013) found that, of the 593 trans men surveyed, 
$51 \%$ of those who were in a relationship prior to transition were still with the same partner at the time of the study, having been together for an average of five years four months. Furthermore, Meier et al. (2013) reported that a supportive partner was a protective factor against mental health difficulties.

\section{Emotional wellbeing}

In comparison to the general population, trans people are statistically more likely to experience a range of mental health difficulties. In a UK based survey of 1054 trans people 88\% reported experiences of depression and 75\% reported experiences of anxiety (McNeil, Bailey, Ellis, Morton, \& Regan, 2012). A further study reported that some trans people were more likely than others to experience mental health difficulties, with support from family and friends being a significant protective factor (Nutbrock, 2002). The increased prevalence of mental health difficulties among trans people, compared to the general population, is believed to be related to minority stress, with 92\% reporting harassment, discrimination or transphobia (McNeil et al., 2012). Minority stress has also been seen to affect partners. One study found that $47.6 \%$ of cisgender men partnered with trans women reported experiencing a clinical level of depression due to stigma and financial hardship (Gamarel, Reisner, Laurenceau, Nemoto, \& Operario, 2014).

It is important to remember that transphobia can also come from within, with higher levels of internalised transphobia correlating with lower self-esteem (Iantaffi, \& Bockting, 2011). Interestingly, higher levels of internalised transphobia appeared to be 
associated with more strongly held stereotypical gender beliefs (Iantaffi, \& Bockting, 2011). These authors argued that this presents a double bind for some trans people, in particular those whose sexual orientation or attractions transgress heteronormativity..

\section{Accessing support}

Many trans people and their partners seek psychological therapy for issues unrelated to transition (Richards \& Barker, 2013; Sanger, 2008), yet some couples do seek psychological support to explore some of the challenges that transition can bring (Buxton, 2007; Malpas, 2012). The following section details key themes from the existing research literature in relation to working therapeutically with this client group, before we go on to present our own research findings.

Some partners report the disclosure of a trans identity as shocking (e.g., Aramburu Alegria, 2010; Buxton, 2007; Gurvich, 1991) and experience a range of emotions in response including sadness, anxiety, stress (Joslin-Roher \& Wheeler 2009), confusion, frustration (Aramburu Alegria, 2010) fear, jealousy (Chase, 2011) helplessness, rejection, anger, self-blame (Gurvich, 1991). The way in which a disclosure of a trans identity occurs can impact partners’ response and adjustment (Malpas, 2012), with those who find out 'by accident' reporting stronger sense of betrayal, anger and mistrust (Gurvich, 1991).

Many partners report difficulties around loss: loss of their own identity, aspects of their partners, family, community, or (heterosexual) privileges (Brown, 2009; Chase, 
2011; Malpas, 2012; Pfeffer, 2014b; Sanger, 2010). Ellis and Eriksen (2002) report that families can go through a process of grieving that is similar to bereavement, passing through six stages from shock to acceptance (Kubler-Ross, 1969). It is also important to challenge the perception that only loss is occurring given this cisgenderism in the implicit assumption that it is 'normal' and expected to remain in the gender assigned at birth (Ansara \& Hegarty, 2014), and the evidence that trans partners are likely to be a great deal less distressed and more fulfilled following transition (McNeil et al,. 2012).

Some partners report that therapists do not know enough about trans issues and call for an increase in the numbers practitioners who have the skills and knowledge to work with them (Aramburu Alegria, 2013; Buxton, 2007; Gurvich, 1991). The British Psychological Society (BPS) (2012) has offered guidelines in the context of trans sexualities, yet they do not include specific recommendations for working with partners. They do recommend that any work around physical sexuality should be orientated on pleasure and self-permission rather than "normative sex", a position supported by some academics and clinicians (Iantaffi, \& Bockting, 2011). Similarly, the World Professional Association of Transgender Health make minimal recommendations for working with partners, simply stating that trans clients and their partners may wish to explore the topics of sexuality and intimacy (Coleman et al., 2012). The sexual identities of both partners, prior to transition, appears to be related to how well the couple adjust to the transition (e.g., Buxton, 2007). Interestingly, women who hold bisexual, queer or fluid sexual identities appear to have more positive experiences of their partner's transition, compared to those who hold binary (heterosexual/lesbian) 
orientations (Brown, 2009; Gurvich, 1991; Nyamora, 2004). There is a distinct lack of research about cisgender men’s experiences of being partnered with trans people (Malpas, 2012). Thus, it is not possible to review how the process may be similar or different for cisgender men.

Several experienced clinicians and researchers have produced more specific recommendations and guidelines for therapists working with trans clients and their partners. Some clinicians argue that in working with GSRD clients therapists need to start by challenging 'either/or' dualism and come to conceptualise gender and sexuality as 'both/and' paradigms (Buxton, 2007; Malpas, 2012). Malpas (2012) argues that it is essential to begin with a comprehensive assessment of both partners including clarifying their goals for therapy, relationship histories, individual, couple and community resilience and resources, taking into account their multiple social identities and intersectionalities. It can be useful for an initial assessment to involve both joint and individual sessions (Malpas, 2012).

Therapy can provide a space to process grief (Ellis \& Eriksen, 2002; Malpas, 2012) increase communication skills, resolve conflict and develop empathy (Gamarel et al., 2014; Malpas, 2012). It can also provide partners with a space to discuss their feelings of uncertainty (Aramburu Alegria, 2010), invisibility (Giammattei, 2015; Malpas, 2012) and fears around personal safety (Joslin-Roher \& Wheeler 2009). Moreover, therapy can enable partners to negotiate changes within their sex lives and relationship configurations (Buxton, 2007; Malpas, 2012; Sanger, 2010) and to consider 
how they will talk to significant others about the transition (Dierckx, Motmans, Mortelmans \& T’sjoen, 2015) including their children (Malpas, 2012). In addition to professional support, many cite the importance of peer and social support (Gurvich, 1991; Joslin-Roher \& Wheeler, 2009; Malpas, 2012; Theron \& Collier, 2013).

This paper presents a section of results from a larger project that explored cisgender partners' understanding of their sexuality and sexual identity over time. The current study aimed to explore the kind of support partners sought, what they found useful about this support, and challenges in accessing it as their partner progressed through transition.

\section{Method}

Participants

Participants were recruited through a variety of United Kingdom (UK) gender, sexual and relationship diverse (GSRD) groups, organisations, and networks between August 2015 and February 2016. Organisations were contacted asking if the details about the study could be circulated to their members and posts were made on relevant forums and social media. Potential participants were encouraged to contact the lead researcher to discuss participation.

For inclusion into the study participants needed to be cisgender and to have had an intimate relationship with a trans person for a minimum of 18 months (at least six months before their transition began and at least a year after this date). This length of 
time was deemed short enough to enable a wide number of participants the opportunity to participate and long enough for participants to have some of experience what it was like to be partnered with a trans person. The relationship did not need to be ongoing at the time of the interview. To investigate the usefulness of support, both partners must have accessed emotional or psychological support over the course of the transition. Whilst many people seek physical intervention as part of their transition many people do not. Thus, it was not deemed necessary for the trans partner to have sought medical intervention or have had contact with a Gender Identity Clinic (GIC).

Though there were several recruitment drives specifically attempting to also attract cisgender men, all six participants were cisgender women. One was partnered with a trans man, three with trans women and two with non-binary people. Five out of the six participants were currently in their relationships at the time of interview. All resided in the UK, five were white British and one white Antipodean. They were aged between 35 and 71 and the length of their relationships ranged from 20 months to 47 years. Two identified as pansexual, one as bisexual/pansexual, two as heterosexual and one as a queer dyke. Of the participants, five had sought individual therapy/counselling and one couple (in addition to individual) had joint therapy. Four had also sought online peer support from other partners. For more information about the participants, their relationships and the kind of support accessed see tables 1 and 2.

[Table 1 near here]

[Table 2 near here] 


\section{Materials}

The interview schedule was constructed by reviewing the current literature and identifying gaps in the field,. Consultation took place with the lead of a peer support group for partners and adjusted after an initial pilot. The questions that relate specifically to this paper, as opposed to the larger study mentioned above, include; 'Can you tell me about any times or events that have been particularly challenging?', 'What, or who helped you through this?' If partner had accessed a GIC, 'What kind of emotional support has been available to you through Gender Identity Services?’ and 'What kind of support would have been useful?'

\section{Procedure}

Participants were interviewed at a location of their choosing and the interviews lasted between 1.5 and 2.5 hours. The interviews were recorded and later transcribed. All participants gave informed consent, were debriefed and offered information detailing further sources of support. All participants were invited to provide a pseudonym for themselves and their partner to protect anonymity. They were all offered a voucher to the value of ten pounds for their participation.

A narrative analysis was conducted on the data, starting with each individual transcript being read through several times whist listening to the recording. Through each reading reflective notes were made paying attention to content, identity 
performance, discourse, and context (Wells, 2011). Potential plots were noted, in how narratives were formed by linking events over time (Riessman, 2002). Close attention was paid to the ways in which the narrators performed their preferred identities in regards to the kind of stories they told (Riessman, 2008). Moreover, the ways in which participants employed or challenged societal discourses were considered (Wells, 2011). This process was completed for each transcript and the last stage involved comparing and contrasting the accounts in order to establish the emerging plot and subplots. Once the plots had been established the transcripts were then re-read with these plots in mind to assess whether these plots were reflected the narratives.

Several measures were put in place to minimise bias. The first author took the lead in the analysis with all three subsequent authors reviewing transcripts and the first author's impressions. Throughout the research process the lead author kept a reflexive journal and discussed aspects of this with the co-authors. The lead author was further part of an additional reflective narrative research group.

\section{Analysis}

\section{The quest to stay together: Who can support me?}

The following presents a section of the research findings from a larger study looking at participant's sexual identities over time in the context of their partner's transition. The strongest narrative that emerged from the data was the "quest to stay together”. Frank's (1995) concept of “Quest Narratives” encapsulates many of the stories participants told: stories of overcoming adversity with the belief that something can be learnt or gained 
from the experience. The plot of the "quest to stay together" was made up of several subplots, one of which is detailed here: “who can support me?”. Within this subplot participants told of a variety of individuals; others like themselves, professionals, and their partners.

\section{Others like me}

Four out of the six participants sought out other partners of trans people online. Louise W and Molly found this support helpful, Janet's experience was mixed and Louise S felt that it was not useful for her. Louise S stated:

I did for a little while, get, um, information sort of a Facebook thing, um, but I think they were all much, it was all a bit sort of soft and wishy washy and I didn't really think that it, that I belonged there.

Like Louise S, Janet felt that she was not able to access much support online as she also felt different to many of the others there: she wanted to talk about the difficulties she was having with her partner, but others did not want to do this as it might be seen as a betrayal. Janet recalled:

Everybody that I've ever come into contact with before who was a partner, very, very, reluctant to talk about their relationship as they felt they were being disloyal.

Janet further elaborated this narrative by stating she felt "being disloyal" was related to 
gender. She spoke about the subjugation of women's needs to explain feelings of guilt some female partners experienced.

We're supposed to make sure that they're alright and we subjugate our own needs, and I think it's that age old bloody thing about being a women and ... women felt very guilty about um, expressing anything negative at all about their relationships.

In contrast, both Louise W and Molly told of positive online experiences. They spoke about how it was helpful to have contact with other people in a similar situation. This served to relieve feelings of being alone and isolated. Louise W explained:

It was interesting and reassuring that, you know, there were other couples going through it, that's, I think that was what I wanted to know ... that we weren't the only ones in our world ... that had to go through that.

Louise spoke about how it was important for them to meet other couples who they saw as similar to themselves: who were happy in their relationship and were committed in their "quest to stay together".

There’s an awful lot of, you know, 'your partner won’t stay with you' ... which is why we got to know Lucy and Anna cos they were still together, it was nice to get to know another couple who were still together. 
The theme of wanting contact with similar others was expanded by Alex who sought support from a friend who was also partnered with a trans person. Not only was her friend Sara partnered with a trans person, but Alex also said "we identify very similarly as femmes, we're very similar age and context”. Thus, having a shared identity on multiple levels deepened this connection and the value of this support. Alex reflected:

I've got an obsession at the moment with echoes and I think that, so there's the witnessing concept in narrative that being witnessed is helpful and healing in itself ... 'Where am I echoed? Where, where bounces back my sound' and I think that's with, like my friend Sara, and a couple of other people, they get it, they, they echo my experience which is bigger than witnessing I think.

Alex spoke about “witnessing”, a process that Devor, (2004) details in his model of identity development. Alex’s concept of “echoes” can also be seen as similar to Devor's, (2004) concept of mirroring; that having something of herself being reflected back to her from another was experienced as validating and supportive.

\section{Therapy}

Five out of the six participants accessed psychological therapy during the period of their partners' transition, with Louise S being the exception. Participants spoke about the reasons why they accessed this support and for some it was important for them to emphasise that their partner's transition was not the main topic covered in their therapy. Louise W explained: 
For me it wasn't, wasn't really trans issues, I suppose that was background stress.

Similarly, Clare stated:

It came up a, a, a few times with my therapist about Sam being trans and we talked about it. I think my therapist was more surprised that it wasn’t really an issue for me.

Both Clare and Louise W's stories challenged the idea that being partnered with a trans person was inherently distressing. Clare emphasised that her relationship was not a dominant theme in her therapy and that her therapist was surprised by this position. This story demonstrates how negative discourses around supposed inherent difficulties in trans partnerships are present in partners' lives as well trans people themselves.

For Molly, seeking couple’s counselling was directly related to her partner's transition. Molly recounted:

Yeah we had it and it was, sort of, it felt like it was a space in which Kate told me lots of big pieces of information and I cried a lot, um, because we were being supervised and then we'd leave at the end of the session and then that would be another week.

This extract highlights the difficulties that Molly and Kate were having in regards to communication in that they were only able to talk when they were "supervised". This 
story further served to provide evidence for Molly’s narratives of loss that feature heavily in her talk: through describing her crying she emphasises the emotional nature of this process.

Alex gave a rich and detailed account of her experiences of therapy and spoke about therapy being “invaluable”. With regards to her previous relationship with a trans person, she stated that therapy allowed her to explore some of her worries about a potential shift in her partner's sexual identity in the context of what she was witnessing in the broader trans communities. She reported that she was worried that her partner might come out as a gay man and used wider discourses about what it means to be human, such as universal fears of abandonment and a desire to be loved, in qualifying her fears.

In the context of her current partner's transition she sought additional therapeutic support. She spoke on several occasions about what Jay’s chest surgery meant for her and her sense of loss around this process. Alex explained:

So I'm gonna do three sessions intensively about the ‘boob thing' because I don't want my sense of loss, or my thinking about their gender, or my gender, or my sexuality and what it all means, to get in the way of the support process.

Throughout her narrative Alex offered several other stories that demonstrated the weight of this loss. She spoke about a party she was planning to say goodbye to Jay's 
"boobs" and a friend who was going to be a "boob surrogate" for her. These stories showed Alex's determination in her quest to stay together in that she wanted to deal with the loss she experienced so she could support her partner when they had surgery.

Some participants specifically spoke about the importance of their therapists having experience of working with GSRD clients. This is demonstrated first by Clare and then Louise W:

She didn't know an awful lot about it. I had to inform her of a number of things.

He did do a bit of 'how are you going to manage to have sex then?' and he was quite, very interested in the sex side of it all.

Clare and Louise W's extracts demonstrate two common experiences of trans people, which are mirrored here by their partners. Clare spoke how about her therapist's lack of knowledge around trans identities resulted in her in taking the role of "educator". Louise W spoke about intrusive questions her therapist asked about their sex lives, a topic that was brought into the room by her therapist's curiosity and not Louise W herself. Her therapist's interest reflected the wider societal discourses about the central role sex is seen to have in "successful” or "well-functioning” relationships (Barker \& Gabb, 2016). 
Janet drew on her therapist's own identity as heterosexual man in justifying his lack of knowledge around GSRD.

I had a therapist who was a heterosexual man ... sort of obviously he was completely out of his experience completely, and so I just explained the basics to him, and then didn't really get into it, cos there was no point, he’s not the person ... to be um, getting into this stuff about.

Like Clare, Janet also positioned herself as an educator as she "explained the basics to him”. She later elaborated stating that she found it difficult to imagine that someone would have the relevant knowledge around GSRD unless they had personal experience themselves.

The therapist's own identity was also relevant to Alex who reported:

I’ve specifically chosen a genderqueer therapist.

\section{Gender identity services}

Five out of the six trans partners had sought medical intervention through a GIC, and three of the participants had attended appointments with their partners (two NHS and one private practice). Both Janet and Louise W attended NHS GICs with their trans partner and reported that they felt there was no support available for them there, yet they were also ambivalent about whether they would have taken it up if it had been 
available. At first Louise W said that she would have accessed support if it had been available, but later reflected that she would have preferred support more locally.

I don't suppose it's, you'd want to be trekking up to London to see people, it needs to be local or accessible from wherever you are, but maybe signposting to places.

As to whether Janet would have liked support within a GIC she was sceptical about the quality of it if it had been available.

Yeah, um, if it had been a good quality service, I mean quite often these things are a bit tokenistic and are not worth taking up.

In this quote Janet drew on her partner's experience of counselling at the GIC, during the time where it was compulsory for people to receive psychological therapy before they could access medical interventions. She also drew on narratives about GICs having a gatekeeping role: the concern that trans people feel they need to tell the clinician what they want to hear in order to access interventions rather than feeling they can be honest about their life and identities (McNeil et al., 2012).

\section{My partner}

Stories about the way couples communicated revealed a major difference between those who were happy in their relationships and those who reported some struggles. Molly’s narrative was thick with stories of pain, loss, distance and living separate lives, which 
she made sense of in terms of the lack of open communication between her and Kate. Molly stated:

I knew there were people using her new name about eight months before I knew what it was ... but that, because, that's because the communication had broken down so she didn't tell me anything, so it just felt like this big secret that I wasn't in on and I think that is still the case.

This extract gives the audience a sense of how excluded Molly felt with the withholding of information experienced as painful. In the above quote Kate was positioned as the person who was not communicating, yet Molly also provided stories of difficulties with communication being a two-way process. Janet also spoke about communication difficulties in her relationship, difficulties that she cited as a significant factor in the breakdown of their relationship. Janet explained:

It felt like the communication stopped ... For me it felt like, ummm, we stopped being able to have a conversation almost completely... he stopped being able to relate to me as a person, sexually.

Here Janet spoke about communication in regards to their sex lives, changes in which she put down to testosterone. She used discourses about gender roles in regards to sexuality and communication styles to make sense of this change she observed in Jo. A further way she made sense of this change was related to Jo becoming focussed on his transition, resulting in other aspects of their lives falling into the background. 
In contrast to Molly and Janet, the other four participants told stories of shared decision making and open conversations they had about their partner's transition and their relationship. Alex explained the value of this:

That's probably why we're doing so well on the whole 'gender sexuality partner' thing is because it does feel that we have a level of communication about it, um, which is great.

\section{Discussion}

Participants spoke about a variety of people who supported them in their "quest to stay together”; others like themselves, professionals, and their partners. For those who sought out similar others, finding peers reduced feelings of isolation. Many researchers and clinicians see peer and social support as a valuable resource for partners (Gurvich, 1991; Joslin-Roher \& Wheeler, 2009; Malpas, 2012; Theron \& Collier, 2013).

In relation to therapeutic support, some participants emphasised that their partner's transition was not a dominant theme during therapy, a point that other partners have also made (Buxton, 2007). Others wished to discuss specific aspects of their partner's transition, with loss being a recurrent theme, a finding consistent with previous research (e.g. Brown, 2009; Chase, 2011; Malpas, 2012; Pfeffer, 2014b; Sanger, 2010). Many of the participants spoke about the limitations of having a therapist who was not trained or experienced in working with GSRD clients, resulting in some of 
them having to take an "educator" role. The lack of suitably trained therapists is a finding reported by previous research (Aramburu Alegria, 2013; Buxton, 2007; Gurvich, 1991;). Two participants also spoke about how the therapist's own identity felt relevant to them, with one specifically seeking out a therapist who identified as gender diverse themselves, a theme that has not, to the authors' awareness, been noted in previous research.

With regards to GICs, those who had attended appointments with their partners reported that they had not received any specific support there. Moreover, they were ambivalent about whether they would have taken it up if it had been offered. The authors are unaware of any other research that has investigated the kind of support partners require from GICs.

As much as others were seen as valuable resources in their "quest to stay together”, the way in which partners worked and communicated with each other to negotiate their relationship, to make important decisions, and to embark on the transition together, seemed to be a major factor in the quality of the relationships they spoke of. This finding is in line with Malpas (2012) who argues that both partners can empower each other by offering empathy, transparency, pacing and reciprocity.

\section{Implications for clinical practice}

Psychological therapy

It is important that clinicians are aware that people access therapy for a variety of 
reasons, regardless of their sexual orientation or gender identity (Richards \& Barker, 2013). Thus, when a partner of a trans person attends therapy, it must not automatically be assumed that it is their partner's transition that has led them there (Buxton, 2007). Moreover, clinicians need to be mindful of the appropriateness of their questions and refrain from asking intrusive questions about bodies or sex lives when not applicable to the therapeutic work. The theme of loss appeared to be particularly relevant and is linked to the topic of sexualities and is discussed in more detail in a separate paper (in preparation). Thus, it is important that therapists can support their clients to process and to acknowledge these losses (Malpas 2012).

The level of communication between the couples appeared to be associated with the quality of relationships that participants reported. Thus, when working with couples it is key for therapists to support clients to find open, honest and respectful ways of communicating with each other (Buxton, 2007; Gamarel et al., 2014; Malpas, 2012; Nyamora, 2004). An aspect of communication for this specific client group was about the trans partner being open about their desires and plans around medical intervention. It is important that the non-transitioning partner is kept informed and feels part of the decision-making process (Buxton, 2007; Gurvich, 1991).

When speaking of the challenges they faced some participants drew on gendered discourses. It may be useful at times to support clients in exploring where their own values, ideas and scripts around gender originate and how these may be serving, or not serving, their relationship (Berry \& Barker, 2015). This can be seen as particularly 
important in the context that more strongly held stereotypical gender beliefs have been found to be associated with high levels of internalised transphobia, which in turn are associated with low self-esteem (Iantaffi, \& Bockting, 2011).

\section{Training}

Some participants in this study reported that they took up an "educator" role with their therapist. This highlights the importance of specific training for clinicians (Aramburu Alegria, 2013; Buxton, 2007; Gurvich, 1991) as it is not appropriate for clients to have to engage in the significant unpaid task of training their therapist in such areas (Richards \& Barker, 2013).

The therapist's own identity was relevant to two of the participants, which brings to the foreground dilemmas therapists may face about whether to disclosure their own identity to clients (Porter, Hulbert-Williams, \& Chadwick, 2015). During training it is important that practitioners consider the benefits and limitations that disclosure of one’s identity may have on the therapeutic relationship, including around gender and sexuality.

\section{Gender identity services}

The two participants who attended GICs with their partners were ambivalent about whether they would have liked to have received support from GICs or not, with the location of them being part of this ambivalence. Thus, it is important for clinicians at 
GICs to liaise with local services to ensure that support that is specific and appropriate is available for partners. The authors are unaware of any previous research about partner's requirements from GICs.

Many of the participants spoke about the value of support from peers (Gurvich, 1991; Joslin-Roher \& Wheeler, 2009; Malpas, 2012; Theron \& Collier, 2013), thus signposting to such organisations from GIC materials and websites would be helpful. This may also encourage practitioners to work with community organisations, both learning from these groups as well as inputting into these services. This highlights the importance of Community Psychology models in working with groups who experience discrimination and oppression (Harper \& Schneider, 2003).

\section{Limitations of the current research}

One limitation of the study is that the small sample size of six participants, consequently results in a lack of generalizability of the findings. However, Wells (2011) suggests that six to eight participants are appropriate when employing narrative methods in order to capture the richness and complexity of the data with sufficient depth. It also seems highly likely that many of the stories drawn on and discussed here will be similar across other partners of trans people, and as discussed above expand on what has been found in previous research. Indeed, they will likely be familiar to any therapists - like ourselves (Jos and Meg-John) who regularly communicate with trans people and their partners in therapeutic and/or community settings. Yet, one may be inclined to be cautious in drawing conclusions in regards to some of the findings. For example, participants were 
ambivalent about support required from GICs, yet only two participants attended a GIC with their partner. Thus, one cannot conclude that partners in general do want support via GICs simply based on this research.

The demographics of the participants were somewhat different to that of previous research in that the women in the present study held a range of sexual identities, whereas previous research seems to have been focussed on either heterosexual women (e.g. Aramburu Alegria, 2013) or sexual minority women (e.g. Brown, 2009; Joslin-Roher \& Wheeler, 2009). This may be considered problematic in the sense that heterogeneity of the sample results in reduced generalisability. However, the aim of qualitative research is to explore topics in depth rather than produce results that can be generalised. On the positive side, one may be able to look at the differences here between the heterosexual and non-heterosexual women. Previous research has suggested that women who hold binary orientations may struggle more than those who hold fluid orientations (Brown, 2009; Gurvich, 1991; Nyamora, 2004). Yet this was not confirmed in the present research, with sexual orientation seeming to have no bearing on how happy the couple were, but rather the level of communication they employed. It is important to note that the wider social context around sexual and gender diversity has changed somewhat over the last 30 years, which consequently impacts on the subjective experience of being partnered with a trans person. This may shed some light on why the heterosexual partners in this study appear to be somewhat less distressed than those in previous research (Gurvich, 1991). 
As much as there was diversity amongst the participants, a further limitation of the project was the lack of cisgender men, which is an issue with the research in this area more broadly (Malpas, 2012). Due to the lack of previous research with cisgender men substantial effort went into seeking them for the study, yet none were successfully recruited. It may be the case that gender diverse people are more likely to be in relationships with cisgender women than men, thus the sample obtained reflects the demographics of trans partnerships. Yet clinicians from adult GICs report that they do meet cisgender men attending appointments with their trans partners (Wiseman-Lee, 2016, personal communication). Alternatively, it may be the case that recruitment was targeted at locations that were primarily populated by women, and/or that women are more generally open to engaging in this kind of research.

\section{Suggestions for future research}

As discussed above, a major limitation of the research was the lack of cisgender men, thus research with this population is required. Moreover, research with people of diverse ethnic and racial backgrounds is also essential. This may be achieved using different sources to recruit participants, with GICs themselves being one potential site.

Several participants reported that they felt their therapists lacked the relevant knowledge. Thus, it would be interesting to examine therapists' own perspectives of working with GSRD clients and to explore what kind of training they would find useful. Moreover, one participant specifically sought out a genderqueer therapist. There has been some research on the experiences of gay therapists in disclosing their sexual 
orientation to clients (e.g. Porter, et al., 2015), yet similar research into the experiences of gender diverse clinicians has not yet been conducted.

\section{Conclusion}

In their "quest to stay together” participants turned to a variety of people to support them. Some accessed personal therapy to discuss aspects of their partner's transition, whilst others reported this was not a topic they felt they needed to discuss in therapy. Many reported they felt their therapist lacked the relevant knowledge around GSRD, thus training of therapists is called for. Communication was deemed to be an important factor in the quality of relationships participants reported, thus this is an area that therapists should explore when working with partners of trans people. Some reported that finding others like themselves was a useful avenue of support and it is recommended that GICs are aware of local groups and resources of which they can signpost partners to. 


\section{References}

Ansara, Y. G., \& Hegarty, P. (2014). Methodologies of misgendering:

Recommendations for reducing cisgenderism in psychological research. Feminism \& Psychology, 24, 259-270. 1-12

Aramburu Alegria, C. (2010). Relationship challenges and relationship maintenance activates following disclosure of transsexualism. Journal of Psychiatric and Mental Health Nursing, 17, 909-916.

Aramburu Alegria, C. (2013). Relational and sexual fluidity in females partnered with male to female transsexual persons. Journal of Psychiatric and Mental Health Nursing, 20, 142-149.

Barker, M. J., \& Gabb, J. (2016). The secrets of enduring love: How to make relationships last. London: Vermilion.

Benjamin, H. (1966). The transsexual phenomenon. New York: Julian Press.

Berry, M. D., \& Barker, M. (2014). Extraordinary interventions for extraordinary clients: Existential sex therapy and open non-monogamy. Sexual and Relationship Therapy, 29, 21-30.

British Psychological Society. (2012). Guidelines and literature review for psychologists working therapeutically with sexual and gender minority clients. Leicester: British Psychological Society.

Brown, N. R. (2009). 'I'm in transition too': Sexual identity renegotiation in sexual minority women's relationships with transsexual men. International Journal of Sexual Health, 21, 61-77. 
Buxton, A. P. (2007). Counseling heterosexual spouses of bisexual or transgender partners. In B. A. Firestein (Ed.), Becoming visible: Counseling bisexuals across the lifespan (pp. 395-416). New York: Columbia University Press.

Chase, L. M. (2011). Wives’ tales: The experience of trans partners. Journal of Gay \& Lesbian Social Services, 23, 429-451.

Coleman, E., Bockting, W., Botzer, M., Cohen-Kettenis, P., DeCuypere, G., Feldman, J., ... Zucker, K. (2012). Standards of care for the health of transsexual, transgender, and gender-nonconforming people, version 7. International Journal of Transgenderism, 13, 165-232.

Devor, A. H. (2004). Witnessing and mirroring: A fourteen stage model of transsexual identity formation. Journal of Gay \& Lesbian Psychotherapy, 8, 41-67.

Dierckx, M., Motmans, J., Mortelmans, D., \& T’sjoen, G. (2015). Families in transition: A literature review. International Review of Psychiatry, 28, 36-43.

Ellis, K. M., \& Eriksen, K. (2002). Transsexual and transgenderist experiences and treatment options. The Family Journal, 10, 289-299.

Frank, A. (1995). The wounded storyteller. Body illness and ethics. University of Chicago Press: Chicago.

Gamarel, K. E., Reisner, S. L., Laurenceau, J. P., Nemoto, T., \& Operario, D. (2014). Gender minority stress, mental health, and relationship quality: A dyadic investigation of transgender women and their cisgender male partners. Journal of Family Psychology, 28, 437-447. 
Giammatei, S.V. (2015). Beyond the binary: Trans-negotiations in couple and family therapy. Family Process, 54, 418-434.

Gurvich, S. E. (1991). The transsexual husband: The wife’s experience. Dissertation Abstracts International, Section A. Humanities and Social Sciences, 52(8), 2837.

Harper, G. W., \& Schneider, M. (2003). Oppression and discrimination among lesbian, gay, bisexual, and transgendered people and communities: A challenge for community psychology. American Journal of Community Psychology, 31, 243252.

Huxley, P. J., Kenna, J. C., \& Brandon, S. B. (1981). Partnerships in transsexulisum: Part two. The nature of the partnership. Archives of Sexual Behaviour, 10, 143160.

Iantaffi, A. \& Bockting, W.O. (2011). Views from both sides of the bridge? Gender, sexuallegitimacy and transgender people’s experiences of relationships. Culture, Health \& Sexuality: An International Journal for Research, Intervention and Care, 13(1), 355-370.

Joslin-Roher, E., \& Wheeler, D.P. (2009). Partners in transition: The transition experiences of lesbian, bisexual and queer identified partners of transgendered men. Journal of Gay and Lesbian Social Services, 21, 30-48.

Kins, E., Hoebeke, P., Heylens, G., Rubens, R., \& De Cuypere, G. (2008). The femaleto-male transsexual and his female partner versus the traditional couple: A comparison. Journal of Sex \& Marital Therapy, 34, 429-438.

Kubler-Ross, E. (1969). On death and dying. London: Macmillan. 
Lawrence, A. A. (2005). Sexuality before and after male-to-female sex reassignment surgery. Archives of Sexual Behavior, 34, 147-166.

Lev, A. I. (2004). Transgender emergence: therapeutic guidelines for working with gender-variant people and their families. New York: The Hawthorn Clinical Practice Press.

Malpas, J. (2012). Can couples change gender? Couple therapy with transgender people and their partners. In J. Bigner \& J. Wetchler (Eds.), Handbook of LGBTaffirmative couple and family therapy (pp. 69-85). New York, NY: Taylor \& Francis.

McNeil, J., Bailey, L., Ellis, S., Morton, J., \& Regan, M. (2012). Trans mental health study 2012. Scottish Transgender Alliance. Retrieved $4^{\text {th }}$ September 2015 http://www.scottishtrans.org/Uploads/Resources/trans mh study.pdf

Meier, S. C., Sharp, C., Michonski, J., Babcock, J. C., \& Fitzgerald, K. (2013). Romantic relationships of female-to-male trans men: A descriptive study. International Journal of Transgenderisum, 14, 75-85.

Nuttbrock, L., Rosenblum, A., \& Blumenstein, R. (2002). Transgender identity affirmation and mental health. International Journal of Transgenderism, 6, 9703.

Nyamora, C. M. (2004). Femme lesbian identity development and the impact of partnering with female-to-male transsexuals. Dissertation Abstracts International, 65, 2642. 
Pfeffer, C. A. (2014b). “I don’t like passing as a straight woman”: Queer negotiations of identity and social group membership. American Journal of Sociology, 120, 144.

Porter, J., Hulbert-Williams, L., \& Chadwick, D. (2015). Sexuality in the therapeutic relationship: An interpretative phenomenological analysis of the experiences of gay therapists. Journal of Gay \& Lesbian Mental Health, 19, 165-183.

Raj, R. (2008). Transforming couples and families: A trans-formative therapeutic model for working with the loved-ones of gender-divergent youth and trans-identified adults. Journal of GLBT Family Studies, 4(2), 133-163.

Richards, C., \& Barker, M. (2013). Sexuality and gender from mental health professionals: A practical guide. London: Sage.

Riessman, C. (2002). Analysis of personal narratives. In J. Gubrium and J. Holstein (Eds.), Handbook of interview research: Context and method. (pp. 695-710). California: Sage Publications Inc.

Riessman, C. (2008). Narrative methods for the human sciences. California: Sage.

Sanger, T. (2008). Chapter 6: Queer(y)ing gender and sexuality: Trans people’s lived experiences and intimate partnerships. In L. Moon (Ed.), Feeling queer or queer feelings?: Radical approaches to counselling sex, sexualities and genders. (pp. 98-105). Hove: Routledge.

Sanger, T. (2010). Trans people's partnerships: Towards an ethics of intimacy. Palgrave Macmillan. 
Serano, J. (2007). Whipping girl: A transsexual women on sexism and the scapegoating of femininity. Berkeley: Seal Press.

Steiner, B. W., \& Bernstein, S. M. (1981). Female-to-male transsexuals and their partners. The Canadian Journal of Psychiatry, 26, 178-182.

Tompkins, A. B. (2014). “There’s no chasing involved”: Cis/trans relationships, “tranny chasers", and the future of a sex-positive trans politics. Journal of Homosexuality, 61, 766-780.

Theron, L., \& Collier, K. L. (2013). Experiences of female partners of masculineidentifying trans persons. Culture, Health \& Sexuality, 15, 62-75.

Wells, K. (2011). Narrative inquiry. Oxford: Oxford University Press. 


\section{Tables}

Table 1: Participant demographic information

\begin{tabular}{|c|c|c|c|c|c|c|c|}
\hline Name & Age & $\begin{array}{l}\text { Gender } \\
\text { identity } \\
\text { (pronoun) }\end{array}$ & Sexual orientation before transition & $\begin{array}{l}\text { Sexual orientation at time of } \\
\text { interview }\end{array}$ & Ethnicity & Area of work & $\begin{array}{l}\text { Geographical location } \\
\text { (participant only) }\end{array}$ \\
\hline 1 Janet & 55 & $\begin{array}{l}\text { Female } \\
\text { (she) }\end{array}$ & $\begin{array}{l}\text { Pansexual (yet in interview she did not } \\
\text { want to position herself) }\end{array}$ & Pansexual & $\begin{array}{l}\text { White British } \\
\text { Jewish }\end{array}$ & $\begin{array}{l}\text { Self- } \\
\text { employed }\end{array}$ & South East, small town \\
\hline Janet’s partner Jo & 64 & Male (he) & Heterosexual (reluctant lesbian) & Heterosexual & White British & Retired & \\
\hline 2- Louise W & 50 & $\begin{array}{l}\text { Female } \\
\text { (she) }\end{array}$ & Heterosexual & Bisexual/Pansexual & White British & Healthcare & South West, large city \\
\hline $\begin{array}{l}\text { Louise W's } \\
\text { partner Rachel }\end{array}$ & 40 & $\begin{array}{l}\text { Female } \\
\text { (she) }\end{array}$ & Bisexual & Pansexual & White British & Healthcare & \\
\hline 3- Molly & 35 & $\begin{array}{l}\text { Female } \\
\text { (she) }\end{array}$ & Heterosexual & Heterosexual & White British & The arts & South West, large city \\
\hline $\begin{array}{l}\text { Molly’s partner } \\
\text { Kate }\end{array}$ & 36 & $\begin{array}{l}\text { Female } \\
\text { (she) }\end{array}$ & $\begin{array}{l}\text { Attracted to women (participant not } \\
\text { comfortable stating an identity on partner's } \\
\text { behalf) }\end{array}$ & $\begin{array}{l}\text { Attracted to women (participant not } \\
\text { comfortable stating an identity on } \\
\text { partner's behalf) }\end{array}$ & White British & The arts & \\
\hline 4-Alex & 38 & $\begin{array}{l}\text { Queer dyke } \\
\text { (she) }\end{array}$ & Queer dyke & Queer dyke & $\begin{array}{l}\text { White } \\
\text { Antipodean }\end{array}$ & Healthcare & South West, large city \\
\hline $\begin{array}{l}\text { Alex’s ex-partner } \\
\text { Mike }\end{array}$ & 48 & $\begin{array}{l}\text { Trans man } \\
\text { (he) }\end{array}$ & Lesbian & Queer & White British & Healthcare & \\
\hline $\begin{array}{l}\text { Alex’s current } \\
\text { partner Jay }\end{array}$ & 45 & $\begin{array}{l}\text { Genderquee } \\
\mathrm{r} \text { (they) }\end{array}$ & Queer dyke & Queer & White British & IT & \\
\hline 5- Louise S & 71 & $\begin{array}{l}\text { Female } \\
\text { (she) }\end{array}$ & Heterosexual & A different sort of heterosexual & White British & Retired & Midlands, small town \\
\hline $\begin{array}{l}\text { Louise S's partner } \\
\text { Dawn }\end{array}$ & 71 & $\begin{array}{l}\text { Female } \\
\text { (she) }\end{array}$ & Heterosexual & $\begin{array}{l}\text { Participant not comfortable stating an } \\
\text { identity on partner's behalf }\end{array}$ & White British & Retired & \\
\hline 6 Clare & 41 & $\begin{array}{l}\text { Cis female } \\
\text { (she) }\end{array}$ & Bisexual & Pansexual & White British & Self employed & Midlands, rural town \\
\hline $\begin{array}{l}\text { Clare's partner } \\
\text { Sam }\end{array}$ & 41 & $\begin{array}{l}\text { Non binary } \\
\text { trans (they) }\end{array}$ & Heterosexual & $\begin{array}{l}\text { Don’t know- heterosexual and } \\
\text { homosexual don’t make sense any more }\end{array}$ & $\begin{array}{l}\text { White } \\
\text { British/Irish }\end{array}$ & Student & \\
\hline
\end{tabular}


Table 2: Information detailing participants’ relationship and their partners' transition

\begin{tabular}{|c|c|c|c|c|c|c|}
\hline Participants & Start of relationship & $\begin{array}{l}\text { Start of transition, date and } \\
\text { defined as... }\end{array}$ & $\begin{array}{l}\text { Length of time } \\
\text { together before } \\
\text { transition }\end{array}$ & Length of relationship & $\begin{array}{l}\text { Signifiers of relationship } \\
\text { commitments }\end{array}$ & Relationship structure \\
\hline 1-Janet and Jo & Autumn 2005 & $\begin{array}{l}\text { Autumn } 2006 \\
\text { Name and pronoun change }\end{array}$ & 1 year & $\begin{array}{l}10 \text { years } \\
\text { Ended Autumn } 2014\end{array}$ & $\begin{array}{l}\text { Married in } 2011 \\
\text { Still legally married though } \\
\text { separated }\end{array}$ & Monogamous \\
\hline $\begin{array}{l}2 \text { Louise } \mathrm{W} \text { and } \\
\text { Rachel }\end{array}$ & Winter 1995 & $\begin{array}{l}\text { Spring } 2012 \\
\text { Seeking medical support, } \\
\text { change of name and pronouns }\end{array}$ & 17 years & 20 years & None & Monogamous \\
\hline $\begin{array}{l}3 \text { Molly and } \\
\text { Kate }\end{array}$ & 2005 & $\begin{array}{l}\text { Autumn } 2014 \\
\text { Change of name and } \\
\text { pronouns, starting hormones }\end{array}$ & 9 years & $\begin{array}{l}10 \text { years } \\
\text { Ongoing }\end{array}$ & $\begin{array}{l}\text { Legally married and hand } \\
\text { fasting ceremony } 2009\end{array}$ & Monogamous \\
\hline $\begin{array}{l}\text { 4-Alex and } \\
\text { Mike }\end{array}$ & $\begin{array}{l}\text { 'Play only } \\
\text { relationship’ in 2009, } \\
\text { ‘serious' relationship } \\
\text { in } 2010 \\
\end{array}$ & $\begin{array}{l}\text { Winter } 2011 \\
\text { Seeking medical support }\end{array}$ & 18 months & $\begin{array}{l}\text { 3-4 years } \\
\text { Ended Winter } 2013\end{array}$ & None & $\begin{array}{l}\text { Open relationship- additional } \\
\text { sexual partners both together and } \\
\text { separately }\end{array}$ \\
\hline 4-Alex and Jay & Winter 2014 & $\begin{array}{l}\text { Spring } 2014 \\
\text { Change of name and } \\
\text { pronouns }\end{array}$ & 3 months & $\begin{array}{l}20 \text { months } \\
\text { Ongoing }\end{array}$ & Bought a house together & $\begin{array}{l}\text { Non-monogamous in intention. } \\
\text { SM play outside of the } \\
\text { relationship, plans to open up the } \\
\text { relationship in the future }\end{array}$ \\
\hline $\begin{array}{l}\text { 5- Louise S and } \\
\text { Dawn }\end{array}$ & 1968 & $\begin{array}{l}\text { Autumn } 2010 \\
\text { Starting hormones } \\
\end{array}$ & 42 years & $\begin{array}{l}47 \text { years } \\
\text { Ongoing } \\
\end{array}$ & $\begin{array}{l}\text { Married } 1969 \\
\text { Reaffirmation of vows in } 2016\end{array}$ & Monogamous \\
\hline $\begin{array}{l}\text { 6- Clare and } \\
\text { Sam }\end{array}$ & Summer 2012 & $\begin{array}{l}\text { Spring } 2015 \\
\text { Change of pronouns }\end{array}$ & 2.5 years & $\begin{array}{l}3.5 \text { years } \\
\text { Ongoing }\end{array}$ & $\begin{array}{l}\text { legal marriage and hand fasting } \\
2016\end{array}$ & $\begin{array}{l}\text { Monogamous at time of } \\
\text { interview, would consider } \\
\text { opening up the relationship in the } \\
\text { future }\end{array}$ \\
\hline
\end{tabular}

